\title{
HTLV-1 proviral load of HAM/TSP patients according to new diagnostic criteria of HAM/TSP
}

\author{
Maria F R Grassi ${ }^{1,2}$, Viviana N Olavarria², Ramon A Kruschewsky², Rita Elizabeth Mascarenhas'², Inês Dourado ${ }^{3}$, \\ Luis C L Correia ${ }^{2}$, Carlos M de Castro-Costa ${ }^{4}$, Bernardo Galvão-Castro ${ }^{1,2^{*}}$ \\ From 15th International Conference on Human Retroviruses: HTLV and Related Viruses \\ Leuven and Gembloux, Belgium. 5-8 June 2011
}

\section{Introduction}

A high HTLV-1 proviral load is described in HTLV-1associated diseases, especially HAM/TSP. However, the cutoff value to define high levels of HTLV-1-proviral load is not well established.

\section{Methods}

281 HTLV-1-infected patients from the HTLV reference center in Salvador, Brazil, were followed from 2005 to 2008. Patients were classified as asymptomatic, possible, probable- and definite-HAM/TSP, in accordance with diagnostic criteria proposed by De Castro-Costa et al 2006. HTLV-1- proviral load was determined using realtime PCR. A receiver operator characteristic (ROC) curve was constructed using only asymptomatic individuals and definite-HAM/TSP patients. The ROC curve was used to predict the proviral load level that differentiates these two groups.

\section{Results}

Out of 281 patients, 189 were asymptomatic and 92 were diagnosed with HAM/TSP (22 possible, 23 probable, 47 definite). The mean HTLV-1 proviral load was higher in possible- $\left(89,104 \pm 93,006\right.$ copies $/ 10^{6}$ PBMC), -probable $\left(175,854 \pm 128,083\right.$ copies $/ 10^{6}$ PBMC) and definite- HAM/TSP patients $(150,667$ $\pm 122,320$ copies $/ 10^{6}$ PBMC), when compared to asymptomatic individuals $\left(27,178 \pm 41,155\right.$ copies $/ 10^{6}$ PBMC) $(\mathrm{p}<0.0001)$. A comparison of all HAM/TSP groups showed the highest proviral loads in probableHAM/TSP patients, yet the differences in mean values were not statistically significant. The ROC curve suggested a value of 49,865 copies/ $10^{6}$ PBMC, with $87 \%$ sensitivity ( $95 \% \mathrm{CI}=74$ to 95$)$ and $81 \%$ specificity (95\% CI $=75$ to 86$)$, as the HAM/TSP patients $(150,667 \pm 122,320$ copies/106 14 PBMC), when compared to asymptomatic individuals $(27,178 \pm 41,155$ copies/106 15 PBMC) ( $<$ 0.0001). A comparison of all HAM/TSP groups showed the highest proviral loads in probable-HAM/TSP patients, yet the differences in mean values were not statistically significant. The ROC curve suggested a value of 49,865 copies $/ 10^{6}$ PBMC, with $87 \%$ sensitivity $(95 \% \mathrm{CI}=74$ to 95$)$ and $81 \%$ specificity ( $95 \% \mathrm{CI}=75$ to 86 ), as the best proviral load cutoff point to differentiate definite HAM/TSP patients from asymptomatic individuals.

\begin{abstract}
Author details
'Advanced Laboratory of Public Health, Fundação Oswaldo Cruz /Bahia, Salvador, Bahia, Brazil. Escola Bahiana de Medicina e Saúde Pública, Bahia, Brazil. ${ }^{3}$ Instituto de Saúde Coletiva, Federal University of Bahia, Bahia, Brazil. ${ }^{4}$ In memoriam, Laboratory of Experimental Neurology and Neurophysiology, Federal University of Ceará, Fortaleza, Ceará, Brazil.
\end{abstract}

Published: 6 June 2011

doi:10.1186/1742-4690-8-S1-A248

Cite this article as: Grassi et al:: HTLV-1 proviral load of HAM/TSP

patients according to new diagnostic criteria of HAM/TSP. Retrovirology 2011 8(Suppl 1):A248

\footnotetext{
* Correspondence: bgalvao@bahiana.edu.br

${ }^{1}$ Advanced Laboratory of Public Health, Fundação Oswaldo Cruz /Bahia,

Salvador, Bahia, Brazil

Full list of author information is available at the end of the article
}

(c) 2011 Grassi et al; licensee BioMed Central Ltd. This is an open access article distributed under the terms of the Creative Commons Attribution License (http://creativecommons.org/licenses/by/2.0), which permits unrestricted use, distribution, and reproduction in any medium, provided the original work is properly cited. 